\title{
Analysis of the association between the LUM rs3759223 variant and high myopia in a Japanese population
}

This article was published in the following Dove Press journal:

Clinical Ophthalmology

31 October 2016

Number of times this article has been viewed

\author{
Shintaro Okui' \\ Akira Meguro' \\ Masaki Takeuchi',2 \\ Takahiro Yamane' \\ Eiichi Okada ${ }^{3}$ \\ Yasuhito lijima ${ }^{4}$ \\ Nobuhisa Mizuki' \\ 'Department of Ophthalmology \\ and Visual Science, Yokohama City \\ University Graduate School of \\ Medicine, Yokohama, Kanagawa, \\ Japan; ${ }^{2}$ Inflammatory Disease Section, \\ National Human Genome Research \\ Institute, National Institutes of Health, \\ Bethesda, MD, USA; ${ }^{3}$ Okada Eye Clinic, \\ Yokohama, Kanagawa, Japan; ${ }^{4}$ Aoto Eye \\ Clinic, Yokohama, Kanagawa, Japan
}

Correspondence: Akira Meguro Department of Ophthalmology and Visual Science, Yokohama City University Graduate School of Medicine, 3-9 Fukuura, Kanazawa-ku, Yokohama, Kanagawa 236-0004, Japan

Tel +81457872683

Fax +8I 45 78I 9755

Email akmeguro@yokohama-cu.ac.jp
Purpose: Many studies have investigated the relationship of the lumican gene (LUM) rs3759223 variant with the risk of high myopia, but the results have been inconsistent and inconclusive. In this study, we investigated whether LUM rs 3759223 is associated with high myopia in a Japanese population.

Methods: We recruited 1,585 Japanese patients with high myopia (spherical equivalent $[\mathrm{SE}]<-9.00$ diopters [D]) and 1,011 Japanese healthy controls (SE $\geq-1.00$ D). The rs3759223 variant was genotyped using the TaqMan assay, and the allelic and genotypic diversity among cases and controls was analyzed according to the SE level.

Results: In the allelic tests, the odds ratio (OR) for the T allele of rs3759223 tended to increase with the progression of SE, and the highest OR (1.56) was found in patients with $\mathrm{SE}<-15 \mathrm{D}$ in both eyes. The OR of the T allele tended to increase with the progression of SE in the additive, dominant, and recessive inheritance models. However, we found no significant associations for any of the alleles or genotype models.

Conclusion: These data support the possibility that the $L U M \mathrm{rs} 3759223 \mathrm{~T}$ allele accelerates the progression of SE in the Japanese population, although no significant associations were observed in this study. Additional genetic studies with larger samples that take into account the degree of SE are needed to clarify the contribution of rs3759223 to the risk of high myopia.

Keywords: high myopia, lumican, association study, polymorphism

\section{Introduction}

Myopia is a type of refractive error and is one of the most common eye disorders in the modern world. High myopia, which is generally defined by a spherical equivalent (SE) refractive error $<-6$ diopters (D) or an axial length (AL) $>26 \mathrm{~mm}$, is associated with an increased risk of various ocular diseases, including retinal detachment, glaucoma, and cataracts. ${ }^{1}$ The prevalence of myopia in East Asian and Southeast Asian countries is higher than the global average. ${ }^{2}$ Therefore, myopia, especially high myopia, is considered an important public health problem in Asian countries.

The etiology of myopia remains uncertain, but it is thought that certain environmental factors, such as near work (reading, studying, and computer use), can trigger the symptoms of myopia in individuals with a particular genetic background. ${ }^{3-6}$ Familial linkage studies have reported 19 genetic loci for myopia to date (MYP1-MYP19), ${ }^{7,8}$ and recent genome-wide association studies have identified many important candidate loci/genes that are implicated in myopia, refractive error, and/or AL elongation in several ethnic populations. ${ }^{9-12}$ 
The lumican $(L U M)$ gene is located on chromosome $12 \mathrm{q} 21.33$ within the MYP3 locus (12q21-q23). LUM is a member of the small leucine-rich proteoglycan family, which regulates collagen fibril assembly ${ }^{13}$ and contributes to the maintenance of tissue-structural homeostasis and the regulation of cell proliferation, migration, and adhesion. ${ }^{14} \mathrm{An}$ animal study found that the eyes of lumican-fibromodulin double-deficient $\left(\mathrm{Lum}^{-/-} \mathrm{Fmod}^{--}\right)$mice show some of the key features of high myopia, such as increased AL, scleral thinning, and retinal detachment. ${ }^{15}$ In 2006, Wang et al ${ }^{16}$ showed that the $L U M$ promoter variant rs 3759223 was significantly associated with high myopia in a Taiwanese population of Han Chinese origin. Subsequently, many studies in Taiwanese, Chinese, or Korean populations have investigated the association of $L U M$ variants, especially rs3759223, with the risk of high myopia, but the results have been inconsistent and inconclusive. ${ }^{17-22}$ Accordingly, the aim of the present study was to investigate whether $L U M$ rs3759223 is associated with high myopia in Japanese patients.

\section{Methods}

\section{Subjects}

We recruited 1,585 unrelated Japanese patients with high myopia ( $\mathrm{SE}<-9.00 \mathrm{D}$ in at least one eye) and 1,011 unrelated healthy Japanese controls ( $\mathrm{SE} \geq-1.00 \mathrm{D}$ in both eyes) at Yokohama City University, Okada Eye Clinic, and Aoto Eye Clinic in Japan. The participants were the same as in our previous study, ${ }^{23}$ and they had similar social backgrounds and resided in the same urban area. All participants were diagnosed by comprehensive ophthalmologic tests, including AL measurement, fundus examination, SE determination, and corneal curvature determination (autorefractor; NIDEK, Gamagori, Japan; ARK-730A, ARK-700A; TOPCON, Tokyo, Japan; KP-8100P, Biometer/Pachymeter AL-2000; Tomey Corporation, Nagoya, Japan). We excluded individuals in the patient cohort who had any genetic diseases that were known to be associated with myopia and/or high myopia, including glaucoma, keratoconus, or Marfan syndrome. We recruited individuals aged 20 years and older for the control cohort to exclude potential myopia patients. Written informed consent was obtained from all participants. The study methodology adhered to the tenets of the Declaration of Helsinki and was approved by the relevant ethics committees at Yokohama City University, the Okada Eye Clinic, and the Aoto Eye Clinic.

\section{DNA extraction and LUM rs3759223 genotyping}

Genomic DNA was extracted from peripheral blood samples using the QIAamp DNA Blood Mini Kit (Qiagen, Hilden,
Germany). Procedures were performed using standardized protocols to ensure uniform DNA quality.

$L U M$ rs3759223 genotyping was performed using the TaqMan $5^{\prime}$ exonuclease assay and a predesigned primerprobe set supplied by Applied Biosystems (Foster City, CA, USA). Polymerase chain reaction (PCR) was performed using a reaction mixture with a total volume of $10 \mu \mathrm{L}$ containing $1 \times$ TaqMan Universal PCR Master Mix (Applied Biosystems), $24 \mathrm{nM}$ of each primer-probe set, and $3 \mathrm{ng}$ of genomic DNA. The PCR conditions were as follows: $95^{\circ} \mathrm{C}$ for 10 minutes, followed by 40 cycles of denaturation at $92^{\circ} \mathrm{C}$ for 15 seconds, and annealing/extension at $60^{\circ} \mathrm{C}$ for 1 minute. The probe fluorescence signal was detected using the StepOnePlus Real-Time PCR System (Applied Biosystems) following the manufacturer's instructions.

\section{Statistical analysis}

The SNP \& Variation Suite 8.4.0 software (Golden Helix, Inc., Bozeman, MT, USA, http://www.goldenhelix.com) was used to test for Hardy-Weinberg equilibrium (HWE) and to perform allelic and genotypic association analyses. Multiple inheritance models were used in the analysis of genotype data to assess each risk allele. Specifically, assuming that $R$ is the risk allele and $\mathrm{nR}$ is the nonrisk allele, we assessed additive ( $R / R$ versus $R / n R$ versus $n R / n R)$, dominant $(R / R+R / n R$ versus $n R / n R)$, and recessive (R/R versus $\mathrm{R} / \mathrm{nR}+\mathrm{nR} / \mathrm{nR}$ ) models. $P$-values and odds ratios (ORs) in genotypic models were adjusted for age and sex ( $P_{\text {adj }}$ and $\mathrm{OR}_{\text {adj }}$, respectively). The $P$ - and $P_{\text {adj }}$-values were determined using the chi-square test and logistic regression, respectively. The meta-analyses of various populations in previous studies were performed using the Mantel-Haenszel method. The possibility of publication bias was assessed by Egger's regression test using the CMA v3 software (Biostat, Englewood, NJ, USA, https://www.meta-analysis.com/index.php).

\section{Results}

The clinical characteristics of the study populations are shown in Table 1. A total of $44.2 \%$ of patients and $41.6 \%$ of controls were male, and the mean ages of the patients and controls were $38.8 \pm 12.2$ years (range: $12-78$ ) and $58.2 \pm 12.3$ years (range: $20-87$ ), respectively. The average SEs of the patients were $-10.94 \pm 2.06 \mathrm{D}$ (range: -4.50 to $-22.75 \mathrm{D}$ ) in the right eye and $-10.82 \pm 2.07 \mathrm{D}$ (range: -4.50 to $-24.50 \mathrm{D}$ ) in the left eye. The average ALs of the patients were $27.55 \pm 1.22 \mathrm{~mm}$ (range: $23.92-33.85 \mathrm{~mm}$ ) for the right eye and $27.51 \pm 1.24 \mathrm{~mm}$ (range: $23.99-34.74 \mathrm{~mm}$ ) for the left eye. For the controls, the average SEs were $0.48 \pm 0.64 \mathrm{D}$ (range: -1.00 to $3.50 \mathrm{D}$ ) in the right eye and $0.48 \pm 0.63 \mathrm{D}$ 
Table I Clinical characteristics of the study population

\begin{tabular}{|c|c|c|}
\hline Parameters & $\begin{array}{l}\text { High myopia cases, }{ }^{a} \\
n=1,585\end{array}$ & $\begin{array}{l}\text { Control subjects, } \\
n=I, 0 I I\end{array}$ \\
\hline Sex, male, \% & 44.2 & 41.6 \\
\hline Mean age, ${ }^{c}$ years & $38.8 \pm 12.2[12,78]$ & $58.2 \pm 12.3[20,87]$ \\
\hline \multicolumn{3}{|c|}{ Mean SE, ' diopter (D) } \\
\hline Right eyes & $-10.94 \pm 2.06[-4.50,-22.75]$ & $0.48 \pm 0.64[-1.00,3.50]$ \\
\hline Left eyes & $-10.82 \pm 2.07[-4.50,-24.50]$ & $0.48 \pm 0.63[-1.00,3.00]$ \\
\hline \multicolumn{3}{|l|}{ Mean $\mathrm{AL},{ }^{\mathrm{c}} \mathrm{mm}$} \\
\hline Right eyes & $27.55 \pm 1.22[23.92,33.85]$ & $23.22 \pm 0.80[18.76,25.96]$ \\
\hline Left eyes & $27.5 \mathrm{I} \pm 1.24[23.99,34.74]$ & $23.20 \pm 0.79[18.99,26.05]$ \\
\hline
\end{tabular}

(range: -1.00 to $3.00 \mathrm{D}$ ) in the left eye. The average ALs were $23.22 \pm 0.80 \mathrm{~mm}$ (range: $18.76-25.96 \mathrm{~mm}$ ) for the right eye and $23.20 \pm 0.79 \mathrm{~mm}$ (range: $18.99-26.05 \mathrm{~mm}$ ) for the left eye.

The genotype frequency of rs3759223 was in HWE in both cases and controls $(P>0.05)$. Table 2 shows the allelic association results for rs3759223 after stratification according to SE in high myopia cases: $<-9.0 \mathrm{D}$ in at least one eye; $<-9.0 \mathrm{D}$ in both eyes; $<-11.0 \mathrm{D}$ in both eyes; $<-13.0$ $\mathrm{D}$ in both eyes; and $<-15.0 \mathrm{D}$ in both eyes. The OR for the $\mathrm{T}$ allele of rs3759223 increased according to the progression of SE, and the highest OR was found in patients with $\mathrm{SE}<-15 \mathrm{D}$ in both eyes $(\mathrm{OR}=1.56,95 \%$ confidence interval $[\mathrm{CI}]=0.79-3.06)$. However, in the allele test, we did not find any significant association in any of the patients who were stratified according to the level of SE $(P>0.05)$.

Table 3 shows the genotypic association results after stratification according to SE in high myopia cases. The OR for the $T$ allele of rs 3759223 tended to increase according to the progression of SE in all of the tested inheritance models, that is, in the additive, dominant, and recessive models. The dominant model of the $\mathrm{T}$ allele showed higher ORs than the additive and recessive models in all of the patient groups that were stratified by the level of SE. The highest OR was found in patients with $\mathrm{SE}<-13 \mathrm{D}$ in both eyes in the dominant model $\left(\mathrm{OR}_{\text {adj }}=1.77,95 \% \mathrm{CI}=0.53-5.83\right)$, while the OR was not calculated in patients with $\mathrm{SE}<-15 \mathrm{D}$ in both eyes in the dominant model because of the absence of the CC genotype in the patient group. Note, however, that the OR before adjustment for age and sex was estimated to be $3.20(95 \% \mathrm{CI}=0.19-53.03)$ in patients with $\mathrm{SE}<-15$ $\mathrm{D}$ in both eyes in the dominant model when a continuity correction $^{24,25}$ for sparse data is applied by adding 0.5 to each cell of the $2 \times 2$ table. However, no significant associations were found in any of genotypic models for any of the patient groups $\left(P_{\text {adj }}>0.05\right)$.

\section{Discussion}

The aim of this study was to assess whether the LUM promoter rs 3759223 variant is associated with the risk of high myopia in a Japanese population. To address this question, we genotyped rs3759223 and assessed the allelic and genotypic diversity in cases and controls according to the level of SE. Because a higher degree of myopia suggests that genetic factors may be involved, this study only included patients with $\mathrm{SE}<-9.00 \mathrm{D}$ in at least one eye. Here, we report that the OR for the $T$ allele of rs3759223 tended to increase with the progression of SE in both allelic and genotypic association tests, although the results did not reach statistical significance. Our findings suggest the possibility that LUM rs3759223 contributes to the risk of very high myopia.

Table 4 summarizes previous studies that investigated the association between $L U M$ rs3759223 and high myopia. In 2006, Wang et $\mathrm{a}^{16}$ reported that there was a statistically significant difference in the genotypic distribution between cases ( $\mathrm{SE}<-10.0 \mathrm{D}$ in both eyes) and controls in Taiwanese subjects of Han Chinese origin. Subsequently, Zhang et al ${ }^{17}$ reported significant associations with high myopia ( $\mathrm{SE}<-6.0$ D in both eyes) for rs3759223 in a Northern Han Chinese population in both genotypic and allelic tests. ${ }^{16}$ However,

Table 2 Allelic association results for LUM rs3759223 after stratification according to spherical equivalent refractive error

\begin{tabular}{|c|c|c|c|c|c|c|c|c|c|c|}
\hline \multirow[t]{2}{*}{ SNP } & \multirow{2}{*}{$\begin{array}{l}\text { Position } \\
\text { on Chr.I2 } \\
\text { (GRCh37) }\end{array}$} & \multirow{2}{*}{$\begin{array}{l}\text { Alleles } \\
(1>2)\end{array}$} & \multirow{2}{*}{$\begin{array}{l}\text { Risk } \\
\text { allele }\end{array}$} & \multicolumn{3}{|c|}{ Phenotype } & \multirow[t]{2}{*}{$\mathbf{n}$} & \multirow{2}{*}{$\begin{array}{l}\text { Risk } \\
\text { allele }(T) \\
\text { frequency, \% }\end{array}$} & \multirow[t]{2}{*}{$P$-value ${ }^{a}$} & \multirow[t]{2}{*}{ OR (95\% Cl) } \\
\hline & & & & & $\begin{array}{l}\text { Criteria of } \\
\text { SE (diopter) }\end{array}$ & $\begin{array}{l}\text { Eye meeting } \\
\text { criteria }\end{array}$ & & & & \\
\hline \multirow[t]{6}{*}{ rs3759223 } & $91,506,783$ & $\mathrm{~T}>\mathrm{C}$ & $\mathrm{T}$ & Controls & $\geq-1$ & Both & $\mathrm{I}, 0 \mathrm{II}$ & 79.9 & & \\
\hline & & & & Cases & $<-9$ & At least one & $\mathrm{I}, 585$ & 80.7 & 0.512 & $\mathrm{I} .05(0.9 \mathrm{I}-\mathrm{I} .2 \mathrm{I})$ \\
\hline & & & & & $<-9$ & Both & 1,252 & 80.8 & 0.485 & $1.05(0.91-1.22)$ \\
\hline & & & & & $<-I I$ & Both & 394 & 81.5 & 0.353 & $1.10(0.90-1.36)$ \\
\hline & & & & & $<-13$ & Both & 130 & 83.8 & 0.134 & $1.30(0.92-1.85)$ \\
\hline & & & & & $<-15$ & Both & 36 & 86.1 & 0.196 & $1.56(0.79-3.06)$ \\
\hline
\end{tabular}

Note: ${ }^{\text {TT }}$ The $P$-values were determined using the chi-square test.

Abbreviations: $\mathrm{Cl}$, confidence interval; OR, odds ratio; SE, spherical equivalent; I, major allele; 2, minor allele; SNP, single nucleotide polymorphism; Chr., chromosome. 
Table 3 Genotypic association results for LUM rs3759223 after stratification according to spherical equivalent refractive error

\begin{tabular}{|c|c|c|c|c|c|c|c|c|c|c|c|}
\hline \multicolumn{3}{|c|}{ Phenotype } & \multirow[t]{3}{*}{$\mathbf{n}$} & \multirow{3}{*}{$\begin{array}{l}\text { Genotype } \\
(T T / C T / C C)^{a} \\
\text { frequency, \% }\end{array}$} & \multirow{3}{*}{ HWE P } & \multicolumn{6}{|c|}{ Genetic models $^{\mathbf{b}}$} \\
\hline & \multirow{2}{*}{$\begin{array}{l}\text { Criteria } \\
\text { of SE } \\
\text { (diopter) }\end{array}$} & \multirow{2}{*}{$\begin{array}{l}\text { Eye } \\
\text { meeting } \\
\text { criteria }\end{array}$} & & & & \multicolumn{2}{|c|}{ Additive model } & \multicolumn{2}{|c|}{ Dominant model } & \multicolumn{2}{|c|}{ Recessive model } \\
\hline & & & & & & $P_{\text {adj }}$ & $\mathrm{OR}_{\mathrm{adj}}(95 \% \mathrm{Cl})$ & $\boldsymbol{P}_{\mathrm{adj}}$ & $\mathrm{OR}_{\mathrm{adj}}(95 \% \mathrm{Cl})$ & $\overline{P_{\text {adj }}}$ & $\mathrm{OR}_{\mathrm{adj}}(95 \% \mathrm{Cl})$ \\
\hline Controls & $\geq-1$ & Both & $\mathrm{I}, 0 \mathrm{II}$ & $64.0 / 31.8 / 4.2$ & 0.808 & & & & & & \\
\hline \multirow[t]{5}{*}{ Cases } & $<-9$ & At least one & $\mathrm{I}, 585$ & $65.1 / 31.1 / 3.8$ & 0.906 & 0.296 & $1.10(0.92-1.32)$ & 0.225 & $1.28(0.86-1.90)$ & 0.495 & I.08 (0.87-I.33) \\
\hline & $<-9$ & Both & 1,252 & $65.4 / 30.7 / 3.9$ & 0.635 & 0.419 & I.08 (0.89-I.3I) & 0.400 & $1.27(0.73-2.19)$ & 0.542 & I.07 (0.85-I.35) \\
\hline & $<-I I$ & Both & 394 & $66.2 / 30.5 / 3.3$ & 0.861 & 0.474 & $1.10(0.85-1.42)$ & 0.523 & $1.28(0.59-2.77)$ & 0.558 & $1.09(0.8 \mathrm{I}-\mathrm{I} .48)$ \\
\hline & $<-13$ & Both & 130 & $70.8 / 26.2 / 3.1$ & 0.694 & 0.123 & $1.34(0.92-1.96)$ & 0.327 & $1.77(0.53-5.83)$ & 0.155 & $1.37(0.88-2.13)$ \\
\hline & $<-15$ & Both & 36 & $72.2 / 27.8 / 0.0$ & 0.333 & 0.146 & $\mathrm{I} .63(0.82-3.27)$ & nd & nd & 0.291 & $1.50(0.69-3.26)$ \\
\hline
\end{tabular}

Notes: ${ }^{a} \mathrm{~T}$ is a risk allele. ${ }^{b}$ Multiple inheritance models were applied in analysis of genotype data to assess risk allele: additive (TT versus CT versus CC), dominant (TT + CT versus CC), and recessive (TT versus CT + CC) models were assessed. The $P_{\text {adj }}$-values were determined using logistic regression.

Abbreviations: $\mathrm{Cl}$, confidence interval; HWE, Hardy-Weinberg equilibrium; nd, not detected; $O \mathrm{R}_{\text {adj; }}$ OR adjusted for age and sex; $P_{\text {adj }}, P$ value adjusted for age and sex; $S E$, spherical equivalent; SNP, single nucleotide polymorphism.

other studies have reported a lack of association between rs3759223 and high myopia in Taiwanese, Chinese, and Korean populations. ${ }^{18-22}$

Recent meta-analyses of the genotype results for rs3759223 that were reported in previous studies suggest that rs3759223 is associated with an increased risk of high myopia in a recessive model of the T allele. ${ }^{26-28}$ Table 4 shows the results of genotypic association tests that used the genotype results reported by each study; the $\mathrm{T}$ allele was associated with an increased risk of high myopia in a recessive model in all of the studies. Our meta-analysis of the results of previous studies also suggested a significant association between rs3759223 and high myopia in a recessive model of the $\mathrm{T}$ allele (meta- $P=1.0 \times 10^{-9}$, meta-OR $=1.47$; Table 4). Egger's regression test showed that there was no significant publication bias in this meta-analysis ( $P=0.184)$. On the other hand, in our Japanese population, the genotype tests showed that the $\mathrm{T}$ allele had a stronger association with high myopia in a dominant model than in a recessive model, regardless of the SE level of the patients (Table 3). This finding is not in line with previous studies. ${ }^{26-28}$

Previous studies that investigated the association of rs3759223 with high myopia have three limitations. The first is the relatively small sample size: all of the studies involved fewer than 300 cases and fewer than 300 controls (Table 4), making them underpowered to detect susceptibility variants, especially modest or small effect variants. This can lead to false-positive or false-negative results in an association study. To overcome this issue, larger sample sizes are required.

The second weakness is that some of the previous studies showed deviations from HWE in controls, and these deviations may be the result of genotyping errors (Table 4). Significant deviations from HWE in controls were found in the two studies by Lin et al ${ }^{19,20}$ that reported that the rs 3759223 $\mathrm{T}$ allele is associated with a 1.53 -fold or a 1.95 -fold increased risk of high myopia, respectively, in a recessive model. In addition, there was a marginal deviation from HWE in the controls in the study by Zhang et al, ${ }^{17}$ who found strong associations in all of the allele and genotype models that they tested. All three of these studies of individuals of Chinese origin used very small sample sizes for the controls $(<100$ subjects), and the frequency of the $\mathrm{T}$ allele was $\sim 30 \%$ in controls (Table 4). However, the 1000 Genomes Project East Asian database shows that the frequency is between $65 \%$ and $75 \%$ in populations of Chinese origin, and $79.8 \%$ and $71.7 \%$ in Japanese and Vietnamese Kinh populations (Table 5). This disparity may result from complex factors in the three studies, including small sample size and possible genotyping errors. Further analyses need to be performed in these populations. Accordingly, we performed a new meta-analysis of previous studies that excluded these three studies. This analysis still showed that there was only a significant association between rs3759223 and high myopia in a recessive model of the $T$ allele (meta- $P=2.0 \times 10^{-4}$, meta-OR $=1.27$; Table 4 ), although the association level was lower than that in the meta-analysis that included all previous studies.

The third weakness of previous studies was that they did not assess associations between rs3759223 and high myopia according to the progression of SE. The present study found that the OR for the $\mathrm{T}$ allele tended to increase with the progression of SE in the Japanese population and suggested that the $\mathrm{T}$ allele has the potential to contribute to the risk of very high myopia. Therefore, an association between rs3759223 and very high myopia should be assessed in other populations.

\section{Conclusion}

In summary, we found that it is possible that the $L U M$ rs3759223 $\mathrm{T}$ allele accelerates the progression of SE in the Japanese population, although no significant associations were 


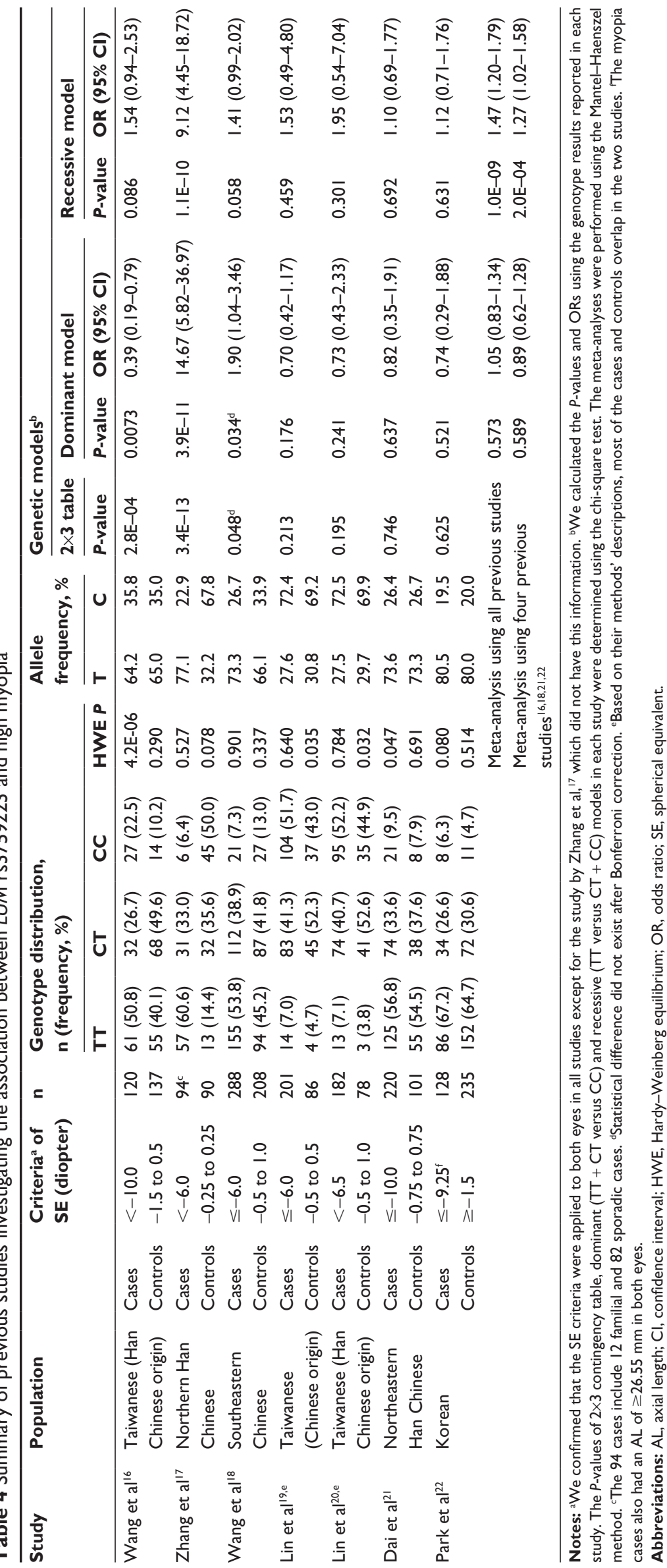


Table 5 Genotype and allele frequencies of the LUM rs3759223 variant in East Asian populations (Phase 3) of the 1000 Genomes Project $^{\mathrm{a}}$

\begin{tabular}{|c|c|c|c|c|c|}
\hline \multirow[t]{2}{*}{ Population } & \multicolumn{3}{|c|}{$\begin{array}{l}\text { Genotype } \\
\text { frequency, } n(\%)\end{array}$} & \multicolumn{2}{|c|}{$\begin{array}{l}\text { Allele } \\
\text { frequency, \% }\end{array}$} \\
\hline & TT & CT & CC & $\mathbf{T}$ & C \\
\hline Chinese Dai in Xishuangbanna, People's Republic of China (CDX), $n=93$ & $4 I(44.1)$ & $42(45.2)$ & $10(10.8)$ & 66.7 & 33.3 \\
\hline Han Chinese in Beijing, People's Republic of China (CHB), $n=103$ & $57(55.3)$ & $39(37.9)$ & $7(6.8)$ & 74.3 & 25.7 \\
\hline Southern Han Chinese, People's Republic of China (CHS), n=l05 & $50(47.6)$ & $45(42.9)$ & $10(9.5)$ & 69.0 & 31.0 \\
\hline Japanese in Tokyo, Japan (JPT), n=104 & $68(65.4)$ & $30(28.8)$ & $6(5.8)$ & 79.8 & 20.2 \\
\hline Kinh in Ho Chi Minh City, Vietnam (KHV), n=99 & $48(48.5)$ & $46(46.5)$ & $5(5.1)$ & 71.7 & 28.3 \\
\hline
\end{tabular}

Note: ${ }^{a}$ Data reprinted with permission from Macmillan Publishers Ltd: Nature ${ }^{29}$ copyright 2015. Available from: http://www. I000genomes.org/

observed in this study. This was probably due to small sample sizes after stratification by SE. To clarify the contribution of rs3759223 to the risk of high myopia, additional larger genetic studies are needed that take into account the degree of SE.

\section{Acknowledgments}

The authors thank all the subjects for their participation in this study and all the medical staff who helped with sample collection and diagnosis.

\section{Disclosure}

The authors report no conflicts of interest in this work.

\section{References}

1. Saw SM, Gazzard G, Shih-Yen EC, Chua WH. Myopia and associated pathological complications. Ophthalmic Physiol Opt. 2005;25(5):381-391.

2. Foster PJ, Jiang Y. Epidemiology of myopia. Eye (Lond). 2014;28(2): 202-208.

3. Lyhne N, Sjølie AK, Kyvik KO, Green A. The importance of genes and environment for ocular refraction and its determiners: a population based study among 20-45 year old twins. Br J Ophthalmol. 2001;85(12):1470-1476.

4. Fan Q, Wojciechowski R, Kamran Ikram M, et al. Education influences the association between genetic variants and refractive error: a meta-analysis of five Singapore studies. Hum Mol Genet. 2014;23(2):546-554.

5. Verhoeven VJ, Buitendijk GH; Consortium for Refractive Error and Myopia (CREAM), et al. Education influences the role of genetics in myopia. Eur J Epidemiol. 2013;28(12):973-980.

6. Goldschmidt E, Jacobsen N. Genetic and environmental effects on myopia development and progression. Eye (Lond). 2014;28(2):126-133.

7. Yu L, Li ZK, Gao JR, Liu JR, Xu CT. Epidemiology, genetics and treatments for myopia. Int J Ophthalmol. 2011;4(6):658-669.

8. Ma JH, Shen SH, Zhang GW, et al. Identification of a locus for autosomal dominant high myopia on chromosome 5p13.3-p15.1 in a Chinese family. Mol Vis. 2010;16:2043-2054.

9. Hysi PG, Wojciechowski R, Rahi JS, Hammond CJ. Genome-wide association studies of refractive error and myopia, lessons learned, and implications for the future. Invest Ophthalmol Vis Sci. 2014;55(5):3344-3351.

10. Fan Q, Barathi VA, Cheng CY, et al. Genetic variants on chromosome 1q41 influence ocular axial length and high myopia. PLoS Genet. 2012; 8(6):e1002753.

11. Cheng CY, Schache M, Ikram MK, et al. Nine loci for ocular axial length identified through genome-wide association studies, including shared loci with refractive error. Am J Hum Genet. 2013;93(2):264-277.

12. Miyake M, Yamashiro K, Tabara Y, et al. Identification of myopia-associated WNT7B polymorphisms provides insights into the mechanism underlying the development of myopia. Nat Commun. 2015;6:6689.
13. Chakravarti S, Magnuson T, Lass JH, Jepsen KJ, LaMantia C, Carroll H. Lumican regulates collagen fibril assembly: skin fragility and corneal opacity in the absence of lumican. J Cell Biol. 1998;141(5): $1277-1286$

14. Nikitovic D, Katonis P, Tsatsakis A, Karamanos NK, Tzanakakis GN. Lumican, a small leucine-rich proteoglycan. IUBMB Life. 2008;60(12): 818-823.

15. Chakravarti S, Paul J, Roberts L, Chervoneva I, Oldberg A, Birk DE. Ocular and scleral alterations in gene-targeted lumican-fibromodulin double-null mice. Invest Ophthalmol Vis Sci. 2003;44(6):2422-2432.

16. Wang IJ, Chiang TH, Shih YF, et al. The association of single nucleotide polymorphisms in the $5^{\prime}$-regulatory region of the lumican gene with susceptibility to high myopia in Taiwan. Mol Vis. 2006;12:852-857.

17. Zhang F, Zhu T, Zhou Z, Wu Y, Li Y. Association of lumican gene with susceptibility to pathological myopia in the Northern Han ethnic Chinese. J Ophthalmol. 2009;2009:514306.

18. Wang P, Li S, Xiao X, et al. High myopia is not associated with the SNPs in the TGIF, lumican, TGFB1, and HGF genes. Invest Ophthalmol Vis Sci. 2009;50(4):1546-1551.

19. Lin HJ, Kung YJ, Lin YJ, et al. Association of the lumican gene functional 3'-UTR polymorphism with high myopia. Invest Ophthalmol Vis Sci. 2010;51(1):96-102.

20. Lin HJ, Wan L, Tsai Y, Chen WC, Tsai SW, Tsai FJ. The association between lumican gene polymorphisms and high myopia. Eye (Lond). 2010;24(6):1093-1101.

21. Dai L, Li Y, Du CY, et al. Ten SNPs of PAX6, Lumican, and MYOC genes are not associated with high myopia in Han Chinese. Ophthalmic Genet. 2012;33(3):171-178.

22. Park SH, Mok J, Joo CK. Absence of an association between lumican promoter variants and high myopia in the Korean population. Ophthalmic Genet. 2013;34(1-2):43-47.

23. Kanemaki N, Meguro A, Yamane T, et al. Study of association of PAX6 polymorphisms with susceptibility to high myopia in a Japanese population. Clin Ophthalmol. 2015;9:2005-2011.

24. Plackett RL. The continuity correction in $2 \times 2$ tables. Biometrika. 1964; 51(3-4):327-337.

25. Cox DR. The continuity correction. Biometrika. 1970;57(1):217-219.

26. Liao X, Yang XB, Liao M, Lan CJ, Liu LQ. Association between lumican gene $-1554 \mathrm{~T} / \mathrm{C}$ polymorphism and high myopia in Asian population: a meta-analysis. Int J Ophthalmol. 2013;6(5):696-701.

27. Feng YF, Zhang YL, Zha Y, Huang JH, Cai JQ. Association of Lumican gene polymorphism with high myopia: a meta-analysis. Optom Vis Sci. 2013;90(11):1321-1326.

28. He M, Wang W, Ragoonundun D, Huang W. Meta-analysis of the association between lumican gene polymorphisms and susceptibility to high Myopia. PLoS One. 2014;9(6):e98748.

29. 1000 Genomes Project Consortium, Auton A, Brooks LD, et al. A global reference for human genetic variation. Nature. 2015;526(7571):68-74. Available from: http://www.1000genomes.org/. Accessed September 16, 2016. 
Clinical Ophthalmology

\section{Publish your work in this journal}

Clinical Ophthalmology is an international, peer-reviewed journal covering all subspecialties within ophthalmology. Key topics include: Optometry; Visual science; Pharmacology and drug therapy in eye diseases; Basic Sciences; Primary and Secondary eye care; Patien Safety and Quality of Care Improvements. This journal is indexed on

PubMed Central and CAS, and is the official journal of The Society of Clinical Ophthalmology (SCO). The manuscript management system is completely online and includes a very quick and fair peer-review system, which is all easy to use. Visit http://www.dovepress.com/ testimonials.php to read real quotes from published authors. 